
November 1935

\title{
DESIGN AND CONSTRUCTION OF AN EXPERIMENTAL DIFFUSION BATTERY
}

\author{
By Max J. Proffitt
}

\section{ABSTRACT}

This paper considers some of the theory behind the design of a 20-cell experimental diffusion battery, built to study the extraction of polysaccharides from jerusalem artichokes. It presents complete structural details. The battery has a working capacity of $1 \mathrm{~kg}$ per cell. The cells were assembled on two floor plans; first, in a single-row straight battery with flux return line; later, in a folded row closed pattern with flux lines of uniform length throughout. In the first arrangement the battery could be divided into 2 batteries of 10 cells each; or into 2 batteries of 6 and 14 cells, respectively; or into 3 batteries of 4,6 , and 10 cells, respectively. The design of the second arrangement provides for the same options in folded units, as well as the splitting of the battery lengthwise into two 10-cell straight units, but the special fittings for multiple folded units have not been installed. Without dividing, the folded arrangement can be operated in two tandem columns which are completely independent, except as to length of charging periods. The folded arrangement provides also for a variety of special regimes of processing, including the preheating of new charges and the application of reagents at whatever point desired, for example, to control the $\mathrm{pH}$ during diffusion. Several diagrams of battery regimes are presented and a number of new terms are introduced to clarify the concepts and to stimulate discussion of a possibly standard nomenclature for the leaching processes in general.

\section{CONTENTS}

I. Introduction

II. Structure of the diffusion battery

III. Action of the diffusion battery

IV. Operation of the battery

V. Auxiliary circulatory system

VI. Reagent dosage

VII. Multiple columns

VIII. Floor-plan patterns _._._.

IX. Construction of the experimental battery

X. Aecessories . .

XI. Costs of construction

XII. Conclusion

XIII. Appendix _.

1. Descriptive legends to accompany figures_............. 460

\section{INTRODUC'TION}

This battery was built at the National Bureau of Standards in 1924 for the purpose of studying the application of the diffusion process to the extraction of the polysaccharides from jerusalem arti- 
chokes as a first step in the manufacture of levulose. Although "beaker" experiments by the author in 1918 had indicated qualitatively that the process could be adapted to this purpose, to verify this conclusion a similar procedure was carried out on a quantitative basis on May 8, 1924, by R. F. Jackson and the author. The results ${ }^{1}$ of this experiment indicated that with artichoke cossettes a term of processing may be required as much as 50 percent greater than that required for an equivalent degree of extraction of beet chips. Accordingly the experimental battery was designed with 20 cells, instead of the 14 which was then prevalent in the American beet-sugar industry. To adapt the equipment to a laboratory scale the working capacity was made $1 \mathrm{~kg}$ of cossettes per cell. The present paper describes the design and structure of the battery in both the original single-row arrangement of the cells, commonly known as the straight floor plan; and also in a double-row arrangement, made in 1926, which will be called the "folded-row" pattern. The general appearance of the battery in the second arrangement is indicated by figure 1. Later papers will deal with some of the experimental results obtained with the battery and its accessories.

\section{STRUCTURE OF THE DIFFUSION BATTERY}

A diffusion battery is essentially an assembly of multiple containers with a system of intercommunicating manifolds of pipe lines and valves arranged for the continuous extraction of soluble substances from particles of solid or semisolid materials. Usually the containers are known as cells or diffusers. The fresh particles are charged through the top opening of the cell, which is closed by a cover; and eventually the spent particles are discharged through a wide bottom opening, which is closed by the door. Most frequently the door opens

1 The extraction was made by macerating $100 \mathrm{~g}$ of artichoke cossettes on a steam bath with successive changes of hot water at 5-minute intervals. In the following summary of results the relative quantities of sugar in the original cossettes, in the various extracts, and in the final residue, are indicated by the quantity of copper precipitated from soxhlet solution by the respective liquids after hydrolysis with acid.

\begin{tabular}{|c|c|c|c|}
\hline Material & $\begin{array}{l}\text { Weight of } \\
\text { material }\end{array}$ & $\begin{array}{c}\text { Weight of } \\
\text { Cu precip- } \\
\text { itate }\end{array}$ & $\begin{array}{l}\text { Equiva- } \\
\text { lent ex- } \\
\text { traction }\end{array}$ \\
\hline Cossettes_.. & $\begin{array}{l}\text { Grams } \\
\quad 100.0\end{array}$ & $\begin{array}{c}\text { Grams } \\
26.70\end{array}$ & Percent \\
\hline $\begin{array}{l}\text { Extract: } \\
\quad 1 \\
\quad 3 \\
\\
4\end{array}$ & $\begin{array}{r}103.8 \\
87.1 \\
106.2 \\
104.3\end{array}$ & $\begin{array}{l}8.706 \\
4.575 \\
3.251 \\
2.239\end{array}$ & $\begin{array}{r}32.61 \\
17.13 \\
12.18 \\
8.39\end{array}$ \\
\hline 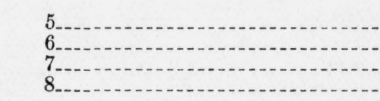 & $\begin{array}{r}98.7 \\
104.5 \\
103.9 \\
103.9\end{array}$ & $\begin{array}{l}1.634 \\
1.155 \\
1.011 \\
0.776\end{array}$ & $\begin{array}{l}6.12 \\
4.33 \\
3.79 \\
2.91\end{array}$ \\
\hline $\begin{array}{l}9 \\
10 \\
11\end{array}$ & $\begin{array}{l}104.6 \\
103.0 \\
100.9\end{array}$ & $\begin{array}{l}0.614 \\
0.589 \\
0.376\end{array}$ & $\begin{array}{l}2.30 \\
2.21 \\
1.41\end{array}$ \\
\hline Total & $\begin{array}{r}1,120.9 \\
371.3\end{array}$ & $\begin{array}{r}24.926 \\
1.514\end{array}$ & $\begin{array}{r}93.38 \\
5.67\end{array}$ \\
\hline Total_. & $1,492.2$ & 26.440 & 99.05 \\
\hline
\end{tabular}

In the commercial extraction of sugar-beet cossettes for a term of processing similar to that indicated above, only about 2 percent of the sugar introduced ordinarily remains in the residues of pulp and pulp water, whereas here nearly 6 percent remained in the pulp and water after the last digestion. 


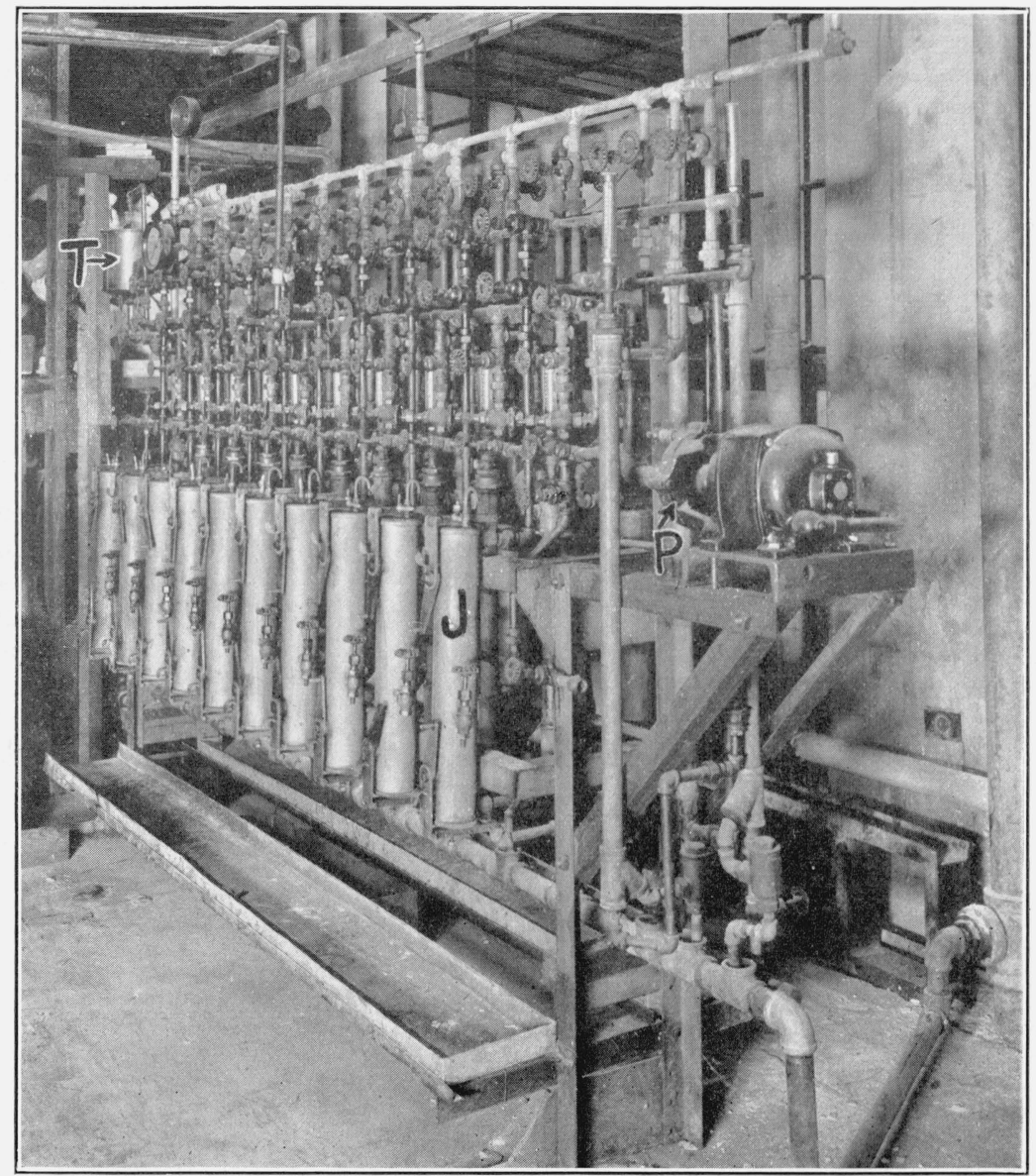

Figure 1.-Battery in the folded-row arrangement.

(See appendix for explanatory text.) 
downwards; occasionally, sidewise. In any particular installation the cells are of uniform capacity. In the beet-sugar industry the usual capacity per cell is between 3 and 7 tons of cossettes. The shape of the cell is cylindrical, usually with conical top and bottom sections, as indicated in figures 2 and 4 . In the present experimental battery, however, the cells are cylindrical throughout their length and their proportions are relatively long and narrow, as illustrated in figure 1. For extracting such materials as cossettes prepared from sugar beets or from Jerusalem artichokes, each cell is provided with a means of heating the material while in process of extraction. Sometimes this is zccomplished by a direct injection of steam, but more often a special surface heater, known as a "calorisator", is provided for each cell. In the diagrams of figures 2,4 , and 5 the calorisators are represented between the cells. In the experimental battery they are placed directly back of the cell, as illustrated in figures 1,9 , and 10 . In the usual commercial installation they are placed about $30^{\circ}$ from this position. In most commercial batteries, as well as in both of the experimental arrangements here discussed, each heater forms a part of the duct leading from the bottom of the cell to the flux line or manifold of that cell. The flux manifold FM in figure 5 is connected through separate valves (1) to the efflux manifold, as indicated at $\mathrm{E}$ in figure 5, and (2) to the inlet manifold IM of the cell next lower in the series. The flux and inlet manifolds may be considered as local or cross headers, each serving an individual cell. The solvent or water manifold, and the efflux manifold, sometimes known as the "solution header" or "juice line", are general manifolds because they serve any cell in the battery. For the same reason the circulation manifolds used in the second arrangement of the experimental battery, as indicated in sketch b of figure 5, are also general manifolds. Figure 5 , sketch a, is a diagrammatic representation of the relations among the cells, the calorisators, and the various manifolds in the first arrangement of the experimental battery. It can serve as well for the usual commercial installation, except that some of these have "cell cut-out" bridge connections between the flux manifolds, which were not provided in either arrangement of the present experimental battery.

It will be observed that liquid can be admitted to any cell in three different ways: through the inlet of the cell, from either (1) the solvent manifold, by opening the valve at W; or (2) the flux manifold of the cell next higher in the series, by opening the valve at $\mathrm{F}_{2}$; or finally, (3) through the port at the bottom of the cell, which is prevailingly the outlet for liquid, by opening the valve at $\mathrm{E}$ to flood the newly charged particles with extract, expel the air, and establish the requisite contact of external liquid. This initial flooding of the particles is simply one phase of the charging of the cell and in this discussion will be called the priming of the charge, or the priming of the cell. Thus a group of any integral number of successive cells less than the number of cells in the battery can be connected together by the valve openings in the transfer ducts in such a way that liquid can flow from the solvent manifold, serially through all the cells in the group, into the efflux manifold from which it passes in two directions, as stated below. In the ordinary method of battery operation, it flows nowhere else. The number of cells in the group is less than the number in the battery because at least one cell must be continually out of service to accommo- 
date the operations of emptying spent charges and admitting fresh charges, including the priming liquid. From the efflux manifold the liquid is delivered partly into the draft of finished extract, and thus withdrawn from the system; and partly into the priming of new charges and therewith briefly returned to the system. The uniform quantity of extract which is withdrawn between the introductions of successive charges is known commonly as the "draft." It is varied to suit the concentration of extractives in the fresh particles and the conditions of operation; but it is practically the same whether the drawing is accomplished concurrently or alternately with the priming.

The valve settings required for any particular case can be inferred from the diagrams of figure 5 and the assembly drawings of figures 9 and 10. Notice that the valve stems of the experimental battery look out from a panel-like arrangement above the cells, while those of a commercial battery generally look up from the floor near the level of the top openings of the cells.

The program of conditions which operate upon each successive charge of material during the term of its processing will be called the regime of operation for that run. The regime of operation includes the course of the solvent as directed by the settings of the valves, the temperature schedule, the proportionate quantity of draft, and all the other applied conditions, as well as the consequential conditions which result from the application of the method to the materials.

\section{ACTION OF THE DIFFUSION BATTERY}

In effect, a diffusion battery is a countercurrent percolator or leacher. The new charges are introduced at regular intervals, here called charging periods, and simultaneously the spent charges are abandoned at the opposite end of the series of active cells. Thus each charge enters the extraction system in the first posture or grade of the series, and remains in this posture during the whole first period of its treatment. During the second period it occupies the second posture; during the $n$th period the final posture. The water or other solvent is introduced to the most nearly spent charge, passed from cell to cell, and finally, as finished extract, withdrawn from the cell containing the newest charge. Thus during the whole term of processing, except the last period, each charge receives a continuous influx of liquid discharged from the contiguous older charge. During the last period it receives a continuous influx of fresh solvent.

Solvent in contact with particles of any degree of exhaustion, or that anywhere in transit between charges, thus containing a smaller or greater concentration of extractives, will be called flood liquid. The flow which carries it from cell to cell, and thus works the changes wrought by the process as a whole, will be called the flux. Although local flows of much larger volume may assist in the work or may even bring about indispensable effects, the flux is the fundamental operator. The method of its action will depend upon whether the flux is continuous or intermittent and whether it is integral or partial; the possible variations are too numerous to discuss exhaustively. The flux is integral when the flood liquid in all of the cells is propelled toward the extract outlet as one intact mass in such a way that its motion comprehends all of the relative movement between particles and flood liquid. It is partial when it does not comprehend all of 
this motion, but is superimposed upon or alternated with a local circulation of the flood liquid or a local agitation of particles and flood liquid produced independently of the flux. The two types are compared diagrammatically in figure 2 .

The relation of the battery to the process may be presented in two aspects, and the importance of each relative to the other depends largely upon the method of operating the flux. In the "standard" method of operation, as applied to the diffusion process in the beetsugar industry, the flux is integral and practically continuous. The whole series of active cells may be regarded as a unit column of $n$ cells' length because the residual extractives in the sap, and likewise
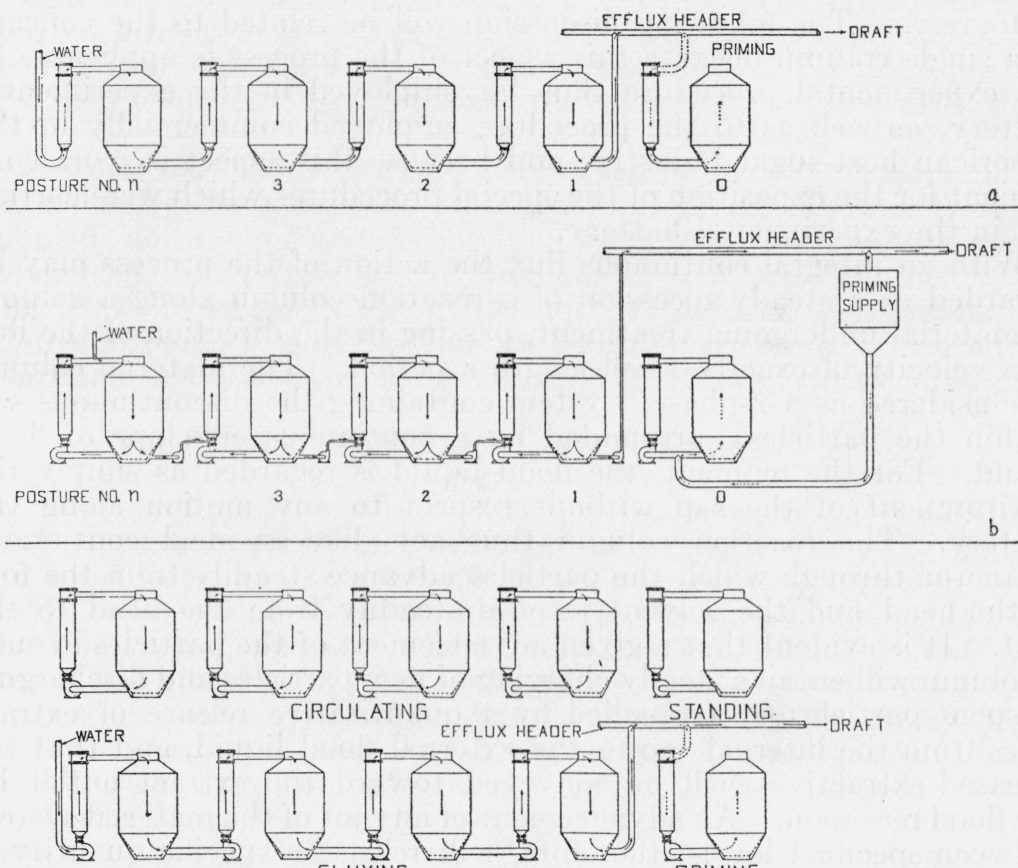

LIRCULATING

STANDING. $\longrightarrow$ DRAFT

POSTURE NO. $n$
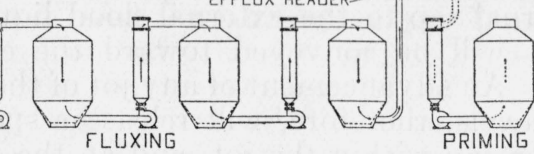

2

Figure 2.-Flow diagrams for three different regimes of diffusion-battery operation.

(See appendix for explanatory text.)

the accumulated extractives in the flood liquid, become distributed along a smooth concentration gradient extending from the solvent inlet at the head of the column ${ }^{2}$ to a region somewhere near the extract outlet at the foot, as indicated diagrammatically at a in figure 3. There are no considerable discontinuities at cell boundaries. With a partial flux, on the contrary, there must be such discontinuities, and in the extreme case of very extensive local circulation or perfect local mixing, there will be no lengthwise gradients through each cell. The concentrations from one end of the series to the other will vary stepwise, as indicated at b in figure 3 . Then the active cells may be seen more conveniently as a battery of separate batch

2 The water inlet is sometimes known as the "tail of the battery", sometimes as the "head". All ought to be agreed as to which is the head and which the foot of a percolator column. 
percolators containing systematically exhausted charges which operate upon the passing flood liquid, and upon which the flood liquid operates.

When the partial flux is continuous the attenuation of the concentration of extractives in each phase of each cell's contents will be continuous with the lapse of time, as illustrated at $\mathrm{c}$ in figure 3 . It will be similar to the attenuation obtained with a continuous integral flux, notwithstanding the stepwise distribution of the concentrations along the battery. The aspect of the process which is connotated by the idea of a battery of separate batch extractors will not be considered further in the present discussion, although that aspect applies with equal strength whether the distribution of concentrations must be described by a pair of continuous curves or by a pair of stepped histograms. The following discussion will be related to the concept of a single column because this aspect of the process is applicable to the experimental procedure thus far employed in the experimental battery, as well as to the procedure employed commercially in the American beet-sugar industry; and because this aspect is more convenient for the exposition of the special procedures which were carried out in the experimental battery.

With an integral continuous flux the action of the process may be regarded as a steady recession of a reaction column along a column of material undergoing treatment, passing in the direction of the flux at a velocity of exactly 1 cell-length a period. The material column is considered as a 2 -phase ${ }^{3}$ system containing the discontinuous sap within the particles, surrounded by a continuous envelope of flood liquid. For the moment, the flood liquid is regarded as simply the environment of the sap without respect to any motion along the battery. The reaction column thus acts like an ideal continuous extractor through which the particles advance steadily from the foot to the head and the solvent recedes steadily from the head to the foot. It is evident that a given advancement of the particles in such a column will entail a steady charging of new particles and discharging of spent particles, accompanied by a quantitative release of extractives from the internal sap to the external flood liquid, and that the released extractives will be conveyed toward the extract outlet by the flood recession. An advancement of any jot of the material system between specified levels, therefore, will release a specific quantity of extractives from the sap within the jot, and at the same time it will dilute the sap's environment of flood liquid by a related specific amount. Thus in a battery column the flux velocity is the sum of the velocity of virtual advancement of the chips toward the head of the reaction column, plus the velocity of virtual recession of the flood liquid toward the foot. The recession is measured by the net rate of discharge of the flood liquid from the system; and it is conveniently expressed as a lengthwise displacement of the flood column, although more commonly expressed as a percentage of the weight of the cossettes charged. The very fact that the reaction column virtually must be fed with the particles continuously, while the material column is charged by cellsful, indicates that there must be always some disparity between the character of the process as a whole and the state of the material in the lower end of the battery column. This disparity can be augmented by inadequate heating at the foot of

\footnotetext{
3 For the present purpose the marc need not be regarded as a third phase. Operatively it is a part
} the apparatus which supports the sap and may sometimes act as a dialysis membrane as well. 
the column, as will be seen later; and the result is such as that indicated by the two pairs of attenuation curves presented at a and $c$ in figure 3.

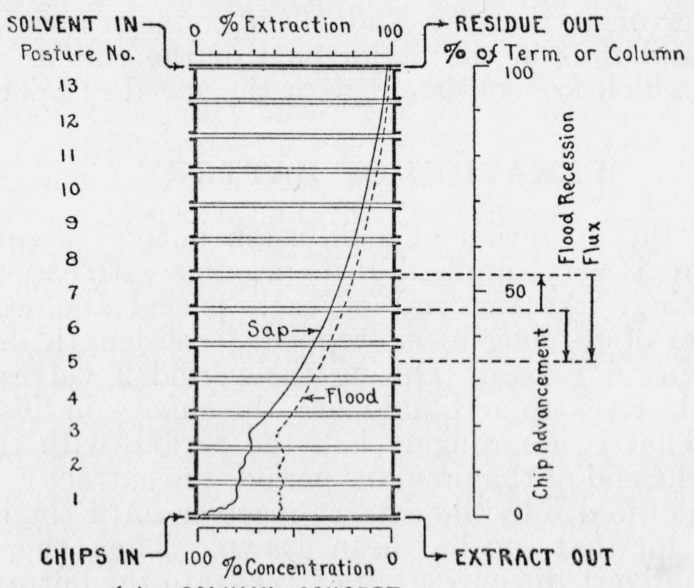

(a) COLUMN CONCEPT
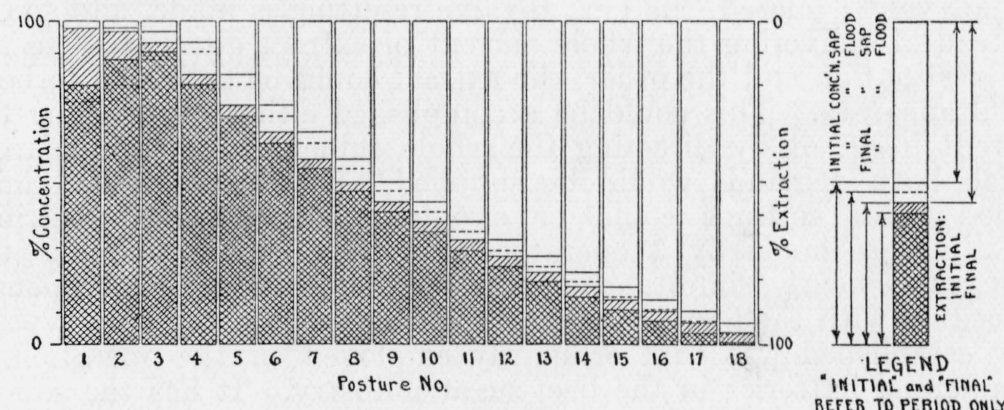

(b) BATTERY CONCEPT

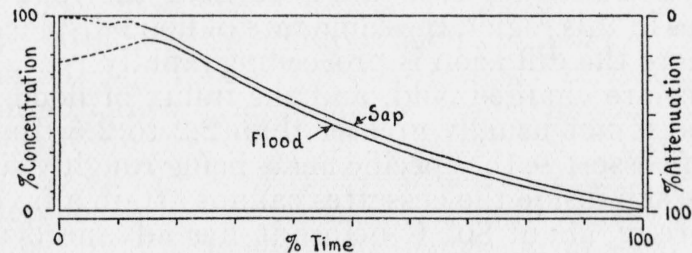

(c) TYPICAL ATTENUATION CURVES WITH CONTINUOUS FLUX (EITHER INTEGRAL OR PARTIAL)

FIGURE 3.-Concepts of diffusion-battery performance.

(See appendix for explanatory text.)

An integral continuous flux in a diffusion battery column of the ordinary type operates in four distinct ways: (1) It propagates the diffusion of extractives. This is done by maintaining a continuous dilution of the flood liquid associated with any jot of the chips where 
a correctly poised relationship among the working conditions has become established. (2) It conveys the diffused extractives out of the system; (3) it limits the thickness of the diffusion layers through its erosive action on the surface films of stagnant flood liquid, and thus speeds the transfer of extractives, and (4) it conveys heat into the material system and thus in the major part of the column sustains rates of diffusion which are consistent with the speed of operation of the battery.

\section{OPERATION OF BATTERY}

Fundamentally the operation of a diffusion battery according to the ordinary regime is very simple, but its practice with experimental precision is exacting. At the end of each period the extraction column, regardless of its length, is stepped 1 cell-length down the battery by resetting 6 valves. During the period 2 valves on the efflux manifold are reset to accommodate the change in destinat of the extract. That is, for roughly half the period, with the valve settings made at the end of the previous period, the extract is directed from the efflux manifold into the extract receiver until the constant quantity selected for that run has been drawn. Then the 2 efflux valves are reset to divert the current of extract into the bottom of the cell which next is to be put into service. When the cell is primed the air vent is closed, the next 6-valve resetting is made, and so on. Instead of delivering the whole current of extract alternately to the one destination and the other, the extract could be delivered to both simultaneously. This could be accomplished either by dividing the current itself, or by directing the whole effluent to a storage from which both demands would be supplied. By either method midperiod valve settings could be avoided. The 6 -valve resettings usually were made by 3 operators who were drilled to make the changes as nearly simultaneously as possible. In the experimental procedure with the first arrangement of the battery, the only type of flow established was that ordinarily employed in the operation of commercial batteries in the beet-sugar industry. It has the serious disadvantage that it does not yield the maximum concentration of extract. The wantage is due to the fact that the method of handling the flux makes no allowance for slow diffusion near the foot of the column, but produces in this region the same rate of flood displacement as in the regions where the diffusion is proceeding rapidly.

Since the cossettes are charged cold, and the influx of flood liquid by weight per period is not usually greater than 2.2 to 2.5 times the weight of a charge of cossettes, the specific heats being roughly similar, it is evident that the sap inside the cossettes cannot attain a favorable diffusion temperature of about $80^{\circ} \mathrm{C}$ before it has advanced up the reaction column a distance of at least 2 cell lengths. This means that in the first postures, at least, the rate of diffusion is so small as to justify but a small fraction of the rate of displacement of the flood liquid along the column permissible in the "diffusion zone", comprising the upper major part of the column where favorable temperatures and correct concentration gradients have become established. On the other hand, for carrying the requisite quantity of heat into the new charges the most favorable rate of flow of the flood liquid is the maximum which can be applied without seriously disturbing the "packing" or mass-structure of the properly deposited chips. This 
rate is at least equal to the permissible rate of flux through the diffusion zone.

In general, where the optimum velocity of relative motion between the flood liquid and the particles is much greater than the most advantageous rate of displacement of the flood liquid along the column, a partial flux is indicated. Generally the continuous type is to be preferred to the intermittent. Where a desirable velocity of continuous integral flux will provide ad equate flow in the diffusion zone, as it usually does in the diffusion of beet or artichoke cossettes, but produces excessive phase translation in the lower sections of the column where diffusion is slow, the column may be divided into a flux section and a preheating section. Where the preheating section can be relatively short, as is the case in the extraction of beet and arti-
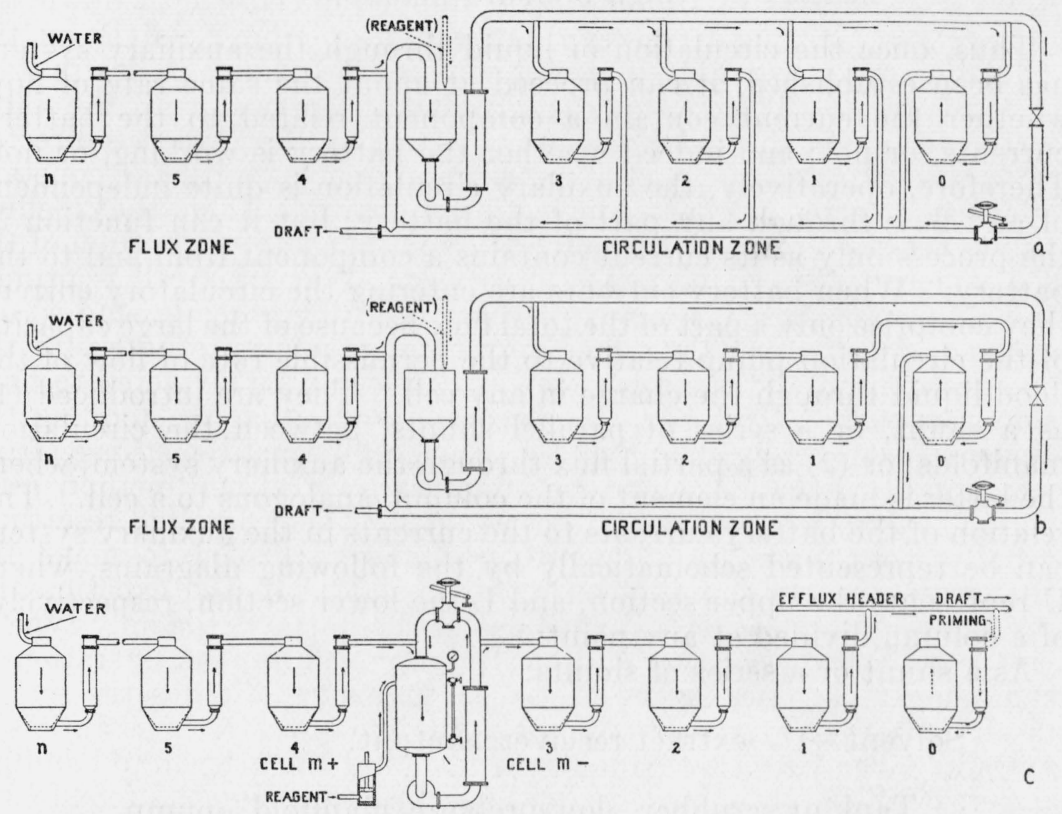

Figure 4.-Flow diagrams with the circulatory system.

(See appendix for explanatory text.)

choke cossettes, the flux through this section can be reduced to zero for all practical purposes. Then the effluent will be withdrawn from the foot of the flux section of the column and directed either into a general extract receiver and circulation supply tank from which the draft of extract or diffusion juice will be withdrawn; or what is nearly equivalent, into the low-pressure circulation manifold from which the draft may be withdrawn as desired; or alternately into the circulation supply and draft receiver. In the preheating section the hot extract will be circulated through the cells, preferably in parallel, as indicated diagrammatically at a in figure 4 , although the operations of valve setting can be simplified somewhat by circulating the liquid serially through the cells, as suggested at $\mathrm{b}$ in figure 4 . 


\section{AUXILIARY CIRCULATORY SYSTEM}

In the folded arrangement of the battery an auxiliary circulatory system is provided for the establishing of this effect, as well as for a variety of other purposes. The principal parts of this auxiliary are the high- and low-pressure circulation manifolds; the circulation pump; the pump supply tank, in place of which a scrubber or gasabsorption tower can be substituted; and a special heater installed in the high-pressure circulation manifold near the tank or scrubber. The flow of liquid through the auxiliary system as it was actually installed (fig. 5, b) is illustrated by the scheme:

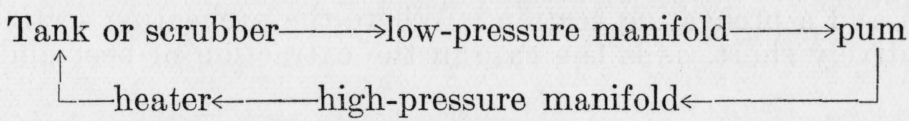

Thus, once the circulation of liquid through the auxiliary system has been established, it can proceed at about the same rate of flow whether the current contain a component related to the battery currents, or not; and indeed whether the battery is working, or not. Therefore, operatively, the auxiliary circulation is quite independent of any flow through any part of the battery; but it can function in the process only as its current contains a component from and to the battery. When battery currents are entering the circulatory current they comprise only a part of the total flow because of the large capacity of the circulation pump relative to the permissible rate of flow of the flood liquid through the charge in any cell. They are introduced (1) as a shunt, or a series of parallel shunts, between the circulation manifolds; or (2) as a partial flux through the auxiliary system, where the latter is made an element of the column, analogous to a cell. The relation of the battery currents to the currents in the auxiliary system can be represented schematically by the following diagrams, where $\mathrm{U}$ represents the upper section, and $\mathrm{L}$ the lower section, respectively, of a column divided at any point:

As a shunt or a series of shunts:

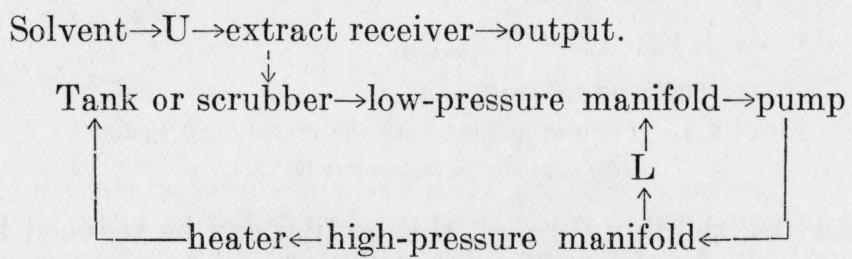

As a partial flux:

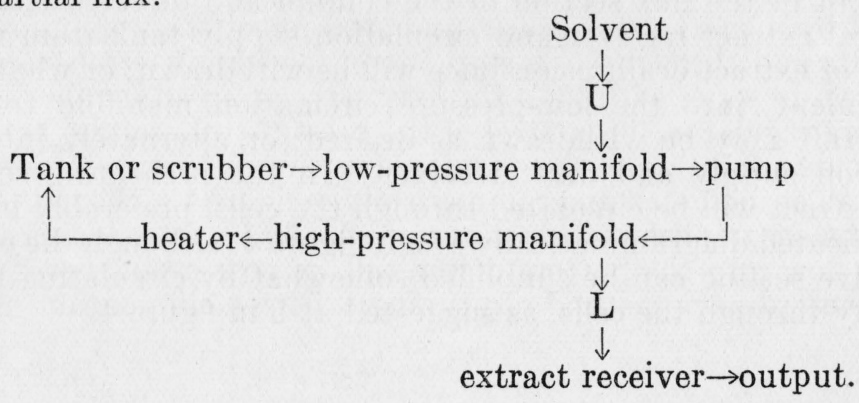


When preheating is applied to any group of cells in parallel (fig. 4, a), the circulatory flow through the group comprises so many shunts between the circulation manifolds, thus:

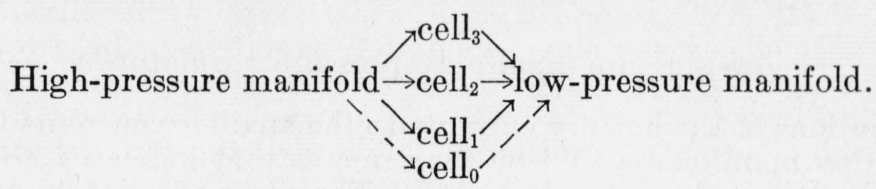

When preheating is applied serially (fig. $4, \mathrm{~b}$ ), the flow is a single shunt between the manifolds, thus:

$$
\begin{aligned}
& \text { High-pressure manifold } \rightarrow \text { cell }_{3} \rightarrow \text { cell }_{2} \rightarrow \text { cell }_{1} \\
& \rightarrow \text { cell }_{0} \rightarrow \text { low-pressure manifold. }
\end{aligned}
$$

The purpose of making the low-pressure manifold the suction line of the pump, as indicated in the schemes presented above, was to

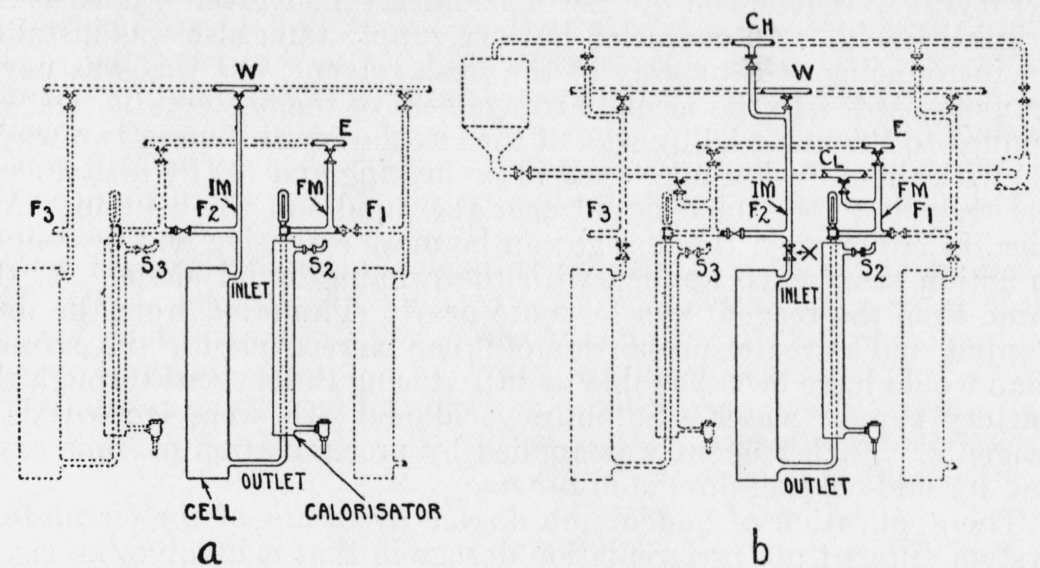

Figure 5.-Pipe connections, (a) straight, (b) folded battery.

(See appendix for explanatory text.)

maintain the pressure head between the manifolds at the practically constant value generated by the pump. Experience indicates that it would have been wiser to place the pump in the position originally selected, directly under the tank, to which it would have been connected by a short suction line, and to connect the 2 manifolds at the opposite end through (1) a stop valve, for complete separation when required, in series with (2) a throttle valve or an adjustable automatic pressure regulator, for control of the pressure differential between the manifolds according to the varying needs of different regimes of operation, all as indicated diagrammatically in figure 4 . Then the priming could be accomplished almost automatically by introducing the circulatory flow into the bottom of the cell in posture 0 , thereby gaining over the ordinary method of priming a better elimination of air and 
perhaps half a period longer time of heating. The flow through the circulatory system then would be described by the scheme:

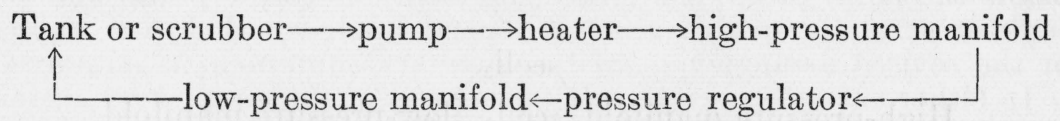

The relations of the battery currents to the auxiliary currents in the 2 circulation manifolds would be the same as that indicated above for the revised arrangement as installed. The advantages of the arrangement as originally devised, over the revised arrangement of the auxiliary system, have been demonstrated on a larger experimental battery. Figure 4 illustrates the original plan, figure 5 the way the system was installed.

\section{REAGENT DOSAGE}

The circulatory system has been used in applying a special treatment which may be called a "dosage" of the material with a reagent. With the straight arrangement of the battery some inconclusive experiments were made on the use of acidified ("converter") juice as the priming liquid. An enameled battery supply tank also was installed for introducing acid by way of the fresh solvent, but this was never actually used. In the second arrangement of the battery, dosage was applied to the material by way of the circulatory system in two ways: (1) with the diffusion juice used in preheating and (2) by introducing the reagent to the flood liquid near the middle of the column. Applied in either way, the dosage can be more extensive and prolonged in action than when applied with the priming liquid alone. At the same time the reagent can be more nearly eliminated from the final residue, and a greater proportion of it can be recovered in the extract, than would have been possible by introducing the reagent through the battery supply water. Sulphuric acid and $\mathrm{SO}_{2}$ were employed as reagents. Each reagent was applied by precirculation in some cases and by mid-column dosage in others.

The application of midcolumn dosage by means of the circulatory system differs from precirculation dosage in that it involves no circulatory flow through a section of the column. Instead, the flux between two postures near the middle of the column is conducted as a partial flow through the circulatory system where the flood liquid involved becomes impregnated with the desired reagent to the preselected concentration. A diagram of the flow is presented at $\mathrm{c}$ in figure 4. The dosage could be produced as well by injecting the reagent at correctly measured rate into the appropriate flux line, or even into a cell; which is to say, it could be injected into the current of flood liquid at any desired "level" along the column. The level at which the dosage is to be applied, by whatever means, will be selected according to the character of the reagent and according to the relative weights assigned to the duration of the action of the reagent as opposed to the degree of its elimination. Ordinarily a level somewhere near the middle of the column will be selected; hence the name. The relation of the circulatory system to the column in this regime is indicated by the scheme:

Effluent from cell $_{\mathrm{m}_{+}} \longrightarrow$ low-pressure manifold $\longrightarrow$ highpressure manifold (as partial flow) $\longrightarrow$ cell $_{\mathrm{m}-\text {, }}$ 
where cell $\mathrm{m}_{+}$is the diffuser situated in the first posture above the point of application of the treatment, cell $\mathrm{m}_{\mathrm{m}}$ that in the first posture below the point of application. The locations of the pump and the tank or scrubber in this scheme depend upon whether the original or the revised arrangement of the auxiliary equipment is employed.

In either case the correct rate of flux out of the circulatory system into the lower part of the column is maintained by keeping the liquid level constant in the supply tank or scrubber; the correct dosage, by keeping the concentration of reagent in the circulating liquid practically constant. The concentration of extractives in the liquid becomes nearly constant also because the flux of the flood liquid through the auxiliary system is a minor component of the total current in the unit, as previously explained. The flood liquid enters the lower section of the column with no considerable gradient of extractive concentration, such as it had before entering the auxiliary, but an effective gradient is soon recovered in recession. Reagent dosage by injection would involve no disturbance of the gradient and no risk of a considerable variation of the rate of flux such as can result from variations in the quantity of liquid impounded in the circulatory system. It will be observed that a certain degree of acidification of the flood liquid could be accomplished by electrolysis in transit. For this purpose the operation of a series of small flux line units would seem at least as promising as a single outside circulatory unit.

The highest concentration of reagent in the flood liquid must exist near the place of application in either method. This produces the remarkable result that, with midcolumn dosage, the net transfer of reagent is first "inward" from the flood liquid to the sap, and finally "outward" from the sap into the flood liquid. The inward trend extends from the foot of the column to the point of application, or somewhat above. Within this region the diffusion of reagent is opposite to the transfer of the natural extractives of the chips, since the latter is predominantly outward, just as in the standard method of battery operation. Nevertheless, because of the greater activity of a reagent such as an acid, the relative degree of its elimination from the final residue may be even greater than that of the natural extractives. Midcolumn dosage seems to be indicated where a prolonged action is to be combined with maximum recovery of reagent, or with minimum contamination of the residue. It should prove especially serviceable in the control of $\mathrm{pH}$ during the diffusion of any material where such control seems advantageous; to the application of a reagent for retarding fermentation in low-temperature diffusion; for fixing proteins during diffusion; and for many other purposes. No similar regime seems to have been applied in the beet-sugar industry, and apparently it is new.

\section{MULTIPLE COLUMNS}

In either the straight or the folded arrangement the experimental battery could be operated as a single extraction column of any number of cells from 2 to 19 , inclusive. The possibility of having as few as one cell unengaged is due to the fact that during even the minimum practical operating period of about 4 minutes, a spent charge could be emptied, the cell cleaned, refilled with cossettes, and primed for reentry into the column. To provide for direct comparison of the relative 
effects of different regimes with respect to any particular factor, either arrangement of the 20 cells could be divided among 2 or 3 independent shorter batteries; or, without dividing into completely independent units, 2 columns could be run in tandem around the whole 20 -cell circuit. Theoretically tandem columns could be run in any standard diffusion battery, but the division into smaller units requires special fittings: (1) For bridging between certain cells and the flux return line, in the straight battery; and between contiguous cells in different rows, or between the opposite ends of each row, in the folded arrangement; and (2) for dividing the flux return line and efflux and circulation manifolds into sections. If multiple columns are operated commercially at present, by either method, the practice certainly is not common. Tandem columns could be applied for increasing the capacity of a battery, with some sacrifice in extraction. They could be applied also in some of the complex extractions which have been described. ${ }^{4}$

In either arrangement of the experimental battery, tandem columns of equal length or of different lengths could be operated; but of course only on the same period-schedule for both columns. Obviously, when 2 columns are operating, at least 2 cells must be out of engagement for the emptying and charging operations. Thus the maximum number of cells engaged in the 2 columns is 18 . In the first arrangement the two effluents could not be kept wholly separate. In the second arrangement, thanks to the extra manifolds available, the two effluents can be taken off separately. For example, the performance of a column with a preheating section can be compared directly with the performance of a standard column with the same or a different total term of processing, depending upon the distribution of the cells between the 2 columns.

The manner of dividing the battery into two or three independent units seems sufficiently evident for either arrangement of the experimental battery. Some of the special valves and connections required for dividing the straight battery are indicated in figure 9 ; and for dividing the folded battery, in figure 10 . In either arrangement the design permits the following optional groupings of the cells: Two 10cell batteries; two batteries of 6 and 14 cells, respectively; or 3 batteries of 4,6 , and 10 cells, respectively. In the first arrangement the shorter units were necessarily of the straight type; in the folded arrangement shorter units of either the straight or the folded type are possible. In the second arrangement the battery can be split lengthwise into 2 straight batteries of 10 cells each, for which a pair of flux return lines is provided to bridge between the opposite ends of each row. These are indicated in figure 10, partially revealed in figure 1. Because tandem columns could accommodate nearly every duplex experiment that it seemed wise to undertake, the special bridge connections between the rows and the special manifold fittings, for dividing the folded battery into smaller folded units, have not been installed. The fundamental simplicity of the pipe connections, per cell, for the two arrangements of the battery is indicated in figure 5. The connections required for dividing the battery into the various optional groupings specified, constitute but slight complications, and these at certain points only.

${ }^{1}$ For example, such an extraction as that described by Schreiber, Geib, Wingfield, and Acree, Ind.Eng. Chem. 22, 497-501 (1930). 
The alterations recommended for new installations of the folded arrangement of a diffusion battery for experimental purposes are: (1) The placing of the circulation pump directly under the tank and the provision of the pressure regulator already mentioned; (2) the insertion of stop-valves at position X, figure 5 , if it is desired to operate 3 columns in tandem; (3) the installation of thermometers at the centers of the cells in place of, or in addition to, those indicated at the tops of the heaters; (4) the replacement of the manually operated valves required in routine operation, with valves operated by air or water pressure, or by electric circuits, actuated by an adjustable device upon which automatic or semiautomatic programs could be set up as desired. The latter is to be considered only where the probable increase in precision, and the relief from the tedium of manual operation, outweigh the very considerable expense involved.

\section{FLOOR-PLAN PATTERNS}

For maximum precision in the flux of the flood liquid, the best floor-plan arrangement of the cells may be classed as the closed patterns where the flux lines are all of uniform length. Of these the most obvious is the familiar circular plan; the most economical of space and the most convenient to construct with standard pipe fittings, as well as the one practical arrangement which is capable of division into shorter closed units, is the folded-row plan. A battery of this type is essentially a collapsed circular battery. The single-row arrangement requires one long flux return line to bridge between the ends, and this results in certain irregularities or unsteadiness of performance which may be inconsequential in industrial practice, but should be avoided in experimental procedure. This drawback, and the additional one of conducting the flux integrally through the incompletely heated lower section of the column, became apparent in the very first experiments with the battery. These considerations, coupled with the desire to experiment more effectively with reagent dosage, led to the design of the folded arrangement of the battery with the circulatory system as described.

\section{CONSTRUCTION OF THE EXPERIMENTAL BATTERY}

To accommodate acid dosage, within the buffering capacity of the artichoke sap, all metallic parts of the battery which could come in contact with the cossettes or flood liquid were constructed of brass, copper, or monel metal. The cells were made long and narrow to provide a maximum linear velocity of the flux at any particular rate of translation of the flood column. The inoperative retention of the flood liquid, which is that proportion of the total time of passage during which the liquid is not in contact with the particles, was limited to the order of that obtained in industrial installations by making the flux transfer lines of $3 / 8$-inch pipe and incorporating as great a proportion of each flux line as possible into the single-pass calorisator attached to the cell. Undesired heating through back pressure of steam from other heaters is avoided by discharging each heater trap into a common condensate manifold which is open to the atmosphere. More accurate control of temperatures near the head of the column could have been attained by discharging the $22381-35-2$ 
traps through a closed water-cooled manifold into a vacuum drip receiver. Details of the construction and assembly of the parts of the battery are presented so fully in figures 6 to 10 , inclusive, that no further description seems necessary.

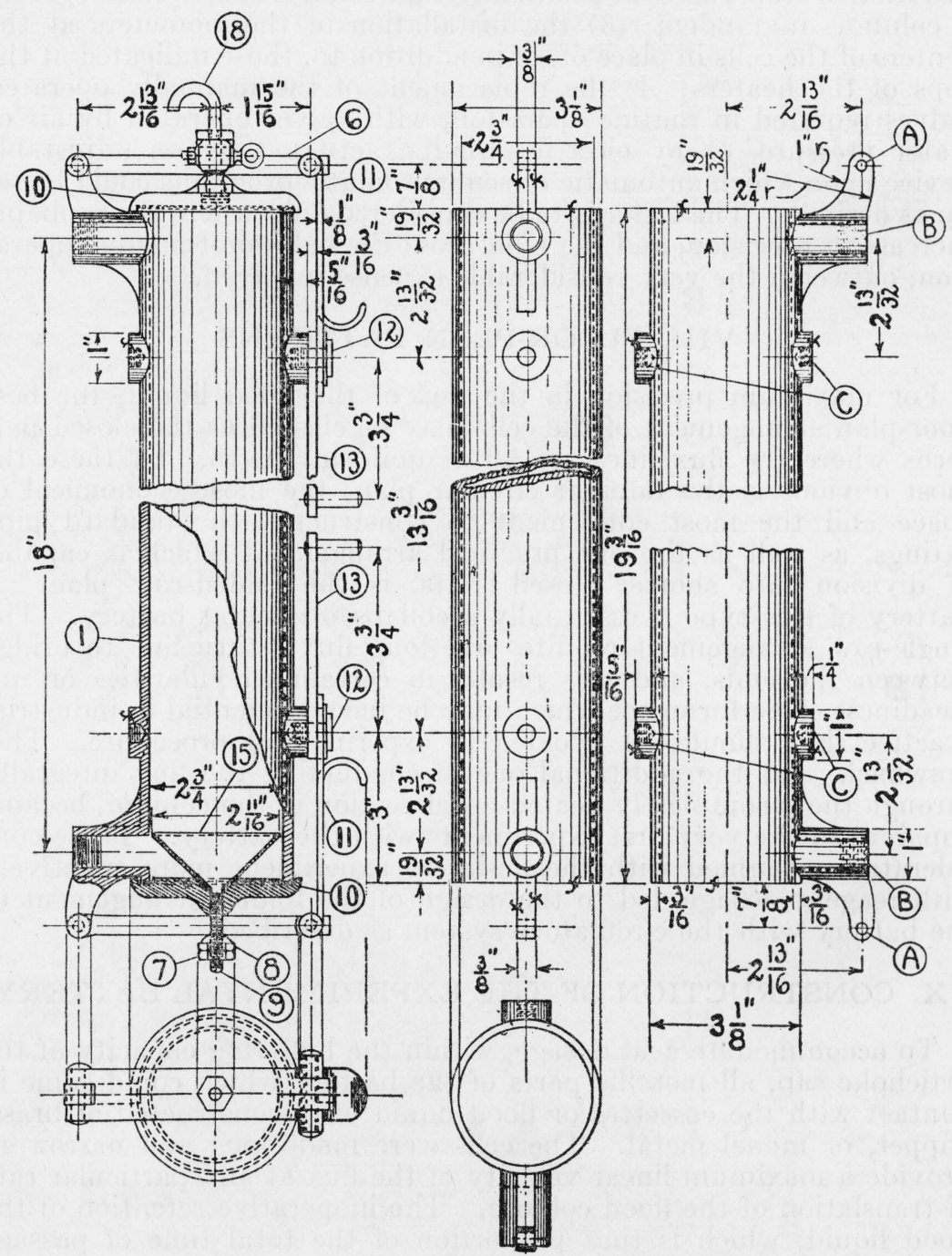

Figure 6.-Cell body, cast brass.

(See appendix for explanatory text.)

\section{ACCESSORIES}

The charging funnels, of which three were provided, are for convenience in introducing equal charges of cossettes without undue risk of accidental loss of material. Their construction is indicated in figure 8. The charge is weighed in the funnel with the gate 
closed; after setting the funnel into the top of the cell and opening the gate, the charge is pushed into the cell and evenly packed with a wooden rod. In many of the experiments the charges were not

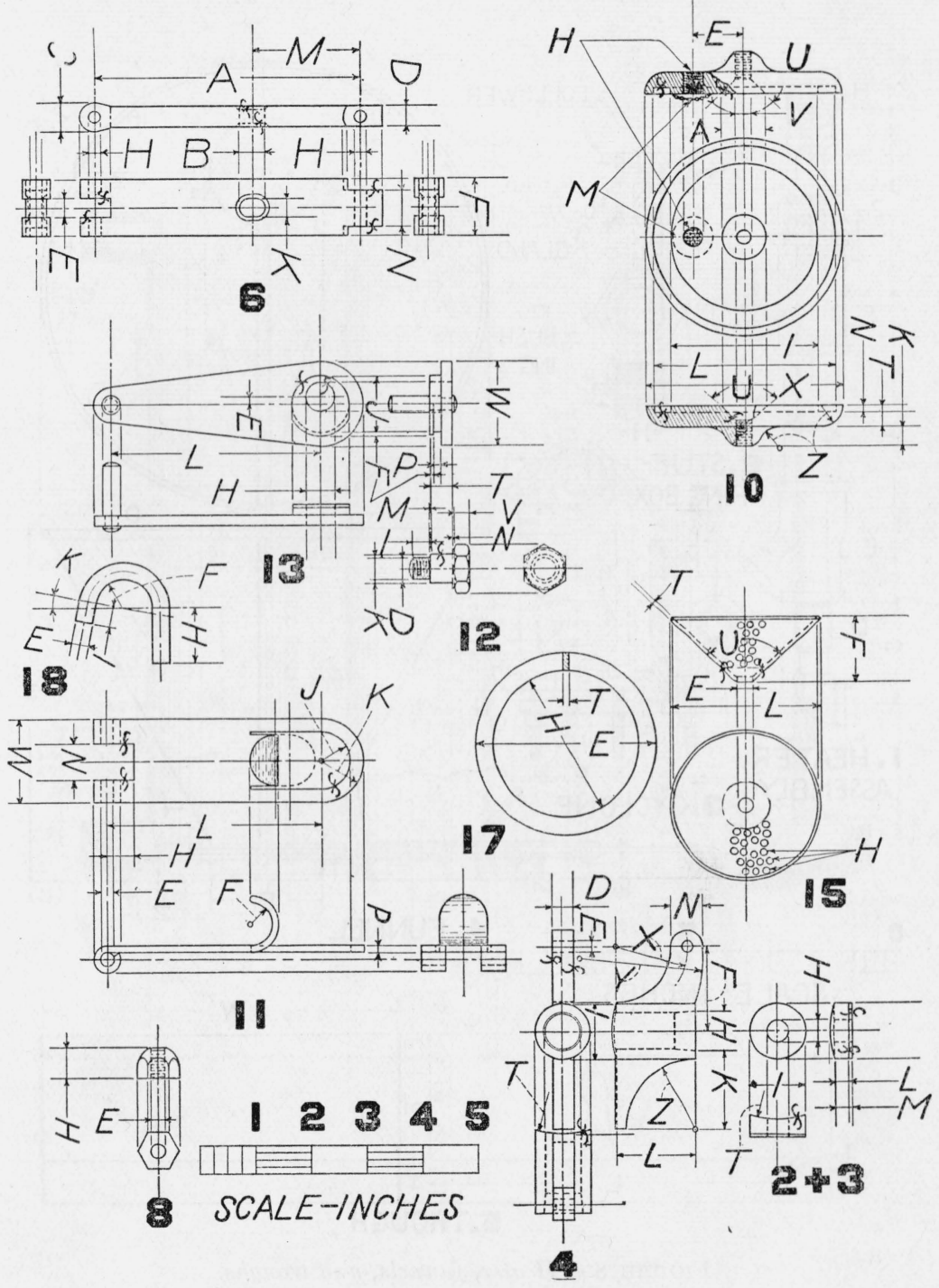

FIGURE 7.-Cell attachments and fittings.

(See appendix for explanatory text.)

weighed individually; in others, although the charges were weighed individually by difference, no effort was made to keep the weights uniform from cell to cell. Instead, the stress was placed on uniform packing to the very top of the cell. Even for this purpose the funnels 
proved useful. All of the funnels were adjusted to the same tare weight and a special brass counterpoise was provided.

The sample receivers consist of 12-quart buckets of galvanized or enameled iron, the latter for use with acidified material. They are fitted with removable perforated metal trays supported on the rims

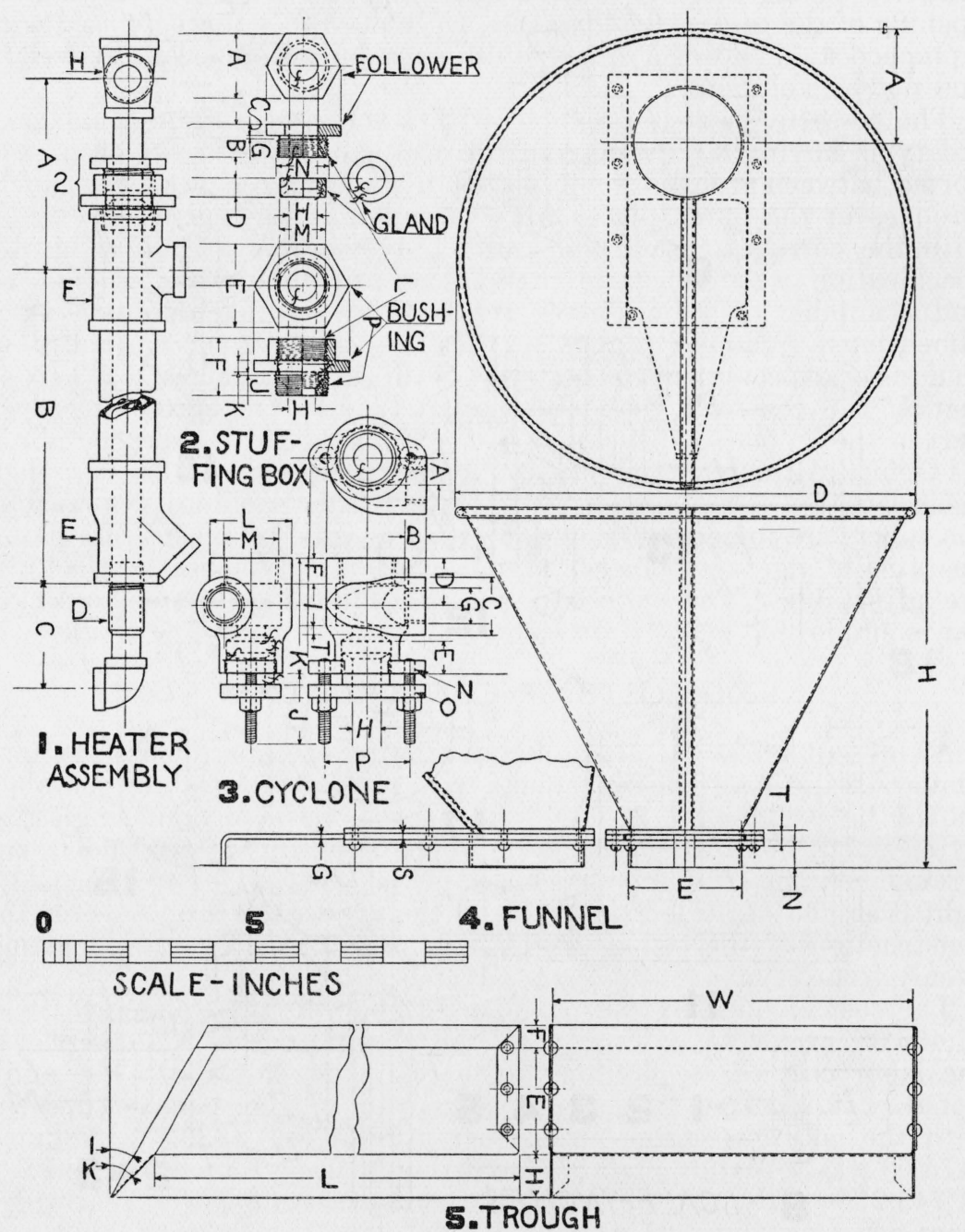

FigURe 8.-Heater, funnels, and troughs.

(See appendix for explanatory text.)

of the buckets by means of attached hook-shaped supports; or instead, with conical woven wire baskets of a size and slope which will permit them to rest in the top of the bucket with the tip some 3 inches above the bottom of the bucket. The purpose of either type of tray is to retain the chips of the sample and allow the associated flood liquid to drain freely and promptly into the bucket. Each sample receiver 
was tared with and without the tray, and each sample was weighed complete and with the tray of drained chips removed.

The draft receiver, or extract receiver, which corresponds to the measuring tank of the beet-sugar industry, consists of a small conicalbottomed brass tank, suspended by means of a bail on the hook of a sensitive spring balance with a large indicating dial. The bottom opening of the tank is fitted with a piece of rubber tubing closed with a pinchcock. Thus the drafts of diffusion juice were taken by weight and not by volume.

The cossette slicer is provided with a single beet-knife of a standard type, having 30 divisions in the $13.7 \mathrm{~cm}$ of width, which is supported between grooved guide plates in a special reciprocating block. Grooves in the guide plates were intended to be registered exactly with the corrugations of the knife; but owing to a shop error this specification was not quite met. The principal result is that an undue number of the cossettes produced by the machine have skew dimensions, although otherwise they are of as good a quality as could be expected from material such as artichokes. In crosssection the cossettes were approximately $0.46 \mathrm{~cm}$ across the open part of the $\mathrm{V}$, and the thickness of the limbs of the $\mathrm{V}$ averaged about $0.14 \mathrm{~cm}$. Although their maximum length was about $10 \mathrm{~cm}$, their mean length was less than $1.2 \mathrm{~cm}$. When the machine is operating, the tubers are forced into contact with the knife by means of a handoperated plunger or follower. The elevation and backset of the knife are adjustable. The knife is bolted to a hinged plate and no rocker bar is employed.

\section{COSTS OF CONSTRUCTION}

At present prices the costs of constructing an experimental battery similar to the folded arrangement with circulatory system complete should be well under $\$ 2,000$. The actual costs of the single-row arrangement in 1924 and the costs of changing this to the folded-row arrangement in 1926 are presented below. As an interesting sidelight it should be stated that bids on the advertised proposals for the construction of the cell bodies and calorisators alone varied rather evenly from $\$ 2,500$ to the accepted low of $\$ 545$.

The cost of building the battery in the straight arrangement was $\$ 1,406.08$, exclusive of design. Of this amount nearly 20 percent was the labor cost of assembling, pipefitting, and painting. The additional cost incurred in the rearrangement of the same equipment with the addition of the circulatory system was $\$ 339.13$, of which $\$ 175.00$ was for labor, mainly pipe fitting, making a final total cost of $\$ 1,745.21$. Although the final labor cost of assembly and rearrangement was thus about 25 percent of the total, the necessary labor cost would have been not more than 20 percent if the second arrangement had been resorted to at first. To the cost of $\$ 1,745.21$ should be added the cost of the particular unit employed for containing the circulating liquid in the special regimes; about $\$ 26.00$ for the scrubber and about $\$ 3.00$ for the small open tank. This completes the cost of the battery proper.

To the cost of the battery there should be added the cost of the accessories, of which the largest item, $\$ 399.45$ for the slicer, is prob- 
ably excessive. The cost of the 3 charging funnels was about $\$ 30.00$, exclusive of design. The sample trays cost from $\$ 0.50$ each for the lightest woven wire basket to $\$ 3.92$ each for the 6 perforated metal trays with hook supports. The buckets cost from $\$ 0.50$ to $\$ 2.00$ each. From 6 to 20 sample receivers were used. The draft receiver tank was made in the laboratory at a cost of about $\$ 1.00$. The spring balances carried no charge, but probably, if new, would have cost about $\$ 10.00$.

\section{CONCLUSION}

1. A practical method has been devised for the heating of the fresh charges in a diffusion battery independently of the conduct of the diffusion process proper, and this results in extracts of higher concentration. The heating can be accomplished without excessive rates of flow, which would disturb the packing of the material in the cells.

2. A new method has been devised for applying a reagent to the material, allowing an extensive duration of contact together with extensive elimination of uncombined reagent from the residue and the recovery of it in the extract.

3. The application of multiple extraction columns in a single battery has been outlined (a) for the comparison of different regimes of operation, either by division of the battery into completely independent units or by operating the columns in tandem around the same circuit; and $(b)$ for the conduct of complicated systems of extraction with different solvents, by operating the columns in tandem over a single circuit. These, and other procedures for which the battery provides, bring out the possibilities of distinct improvements in the design of extraction equipment, especially in its application to new uses.

\section{APPENDIX}

\section{DESCRIPTIVE LEGENDS TO ACCOMPANY FIGURES}

Figure 1.-Battery in the folded-row arrangement.

The open circulation tank $\mathrm{T}$ is in place at the far end; the circulation pump P at the near end. Reading from the top downward, the horizontal rows of $3 / 8$-inch valves in the panel-like mass arrangement above the long cylindrical cells $\mathrm{J}$ are of the kinds and for the purposes indicated below:

Row 1 , globe valves connecting the steam manifold with the calorisators and heaters; row 2, angle valves connecting the solvent manifold with the inlet manifolds; row 3, cross valves connecting the high-pressure circulation manifold with the inlet manifolds; row 4, gate valves connecting the efflux manifold with the 20 flux manifolds; row 5, cross valves set at a conspicuous angle with the plane of the panel and connecting the low-pressure circulation manifold with the flux manifolds; row 6, gate valves connecting each of the 20 flux manifolds with the inlet manifolds of the next succeeding cell.

The valves applied to the sides of the cells, below their middles, are for the sampling of the flood liquid. They are not indicated in any of the drawings. Other parts can be identified by comparison of this figure with figures $5,6,7$, and 10 .

Figure 2.-Flow diagrams for three different regimes of diffusion-battery operation

Only the lines actually in service are indicated. The flow with an integral continuous flux is illustrated at a; with a continuous partial flux at $b$; and with an intermittent partial flux, where the flux is operated integrally while it is flowing, but alternately with local circulations, is illustrated at c.

FiguRe 3.-Concepts of diffusion-battery performance.

At a all of the operating cells (diagramed as very short and wide) are supposed to constitute a single ex. tractor column, as though all of them were placed end to end. A graph of the attenuation of the sap and flood with lapse of processing time coincides with a graph of the distribution of concentrations along the column, the latter moving downward 1 cell-length during a period.

At $b$ the operating cells are conceived as constituting so many individual percolators or extraction columns containing charges in various but systematically related degrees of exhaustion. The gradient of extractives-concentration in each liquid phase, from end to end of a cell, may be anything from zero to a gradient which is perfectly continuous with the gradients through the contiguous cells. This concept is especially usoful where the flux is partial, but of course applies to any case. Whether the flux be integral or partial, so long as it is continuous the attenuation of the concentration of extractives in each phase in each cell is continuous, as indicated at $\mathrm{c}$. 


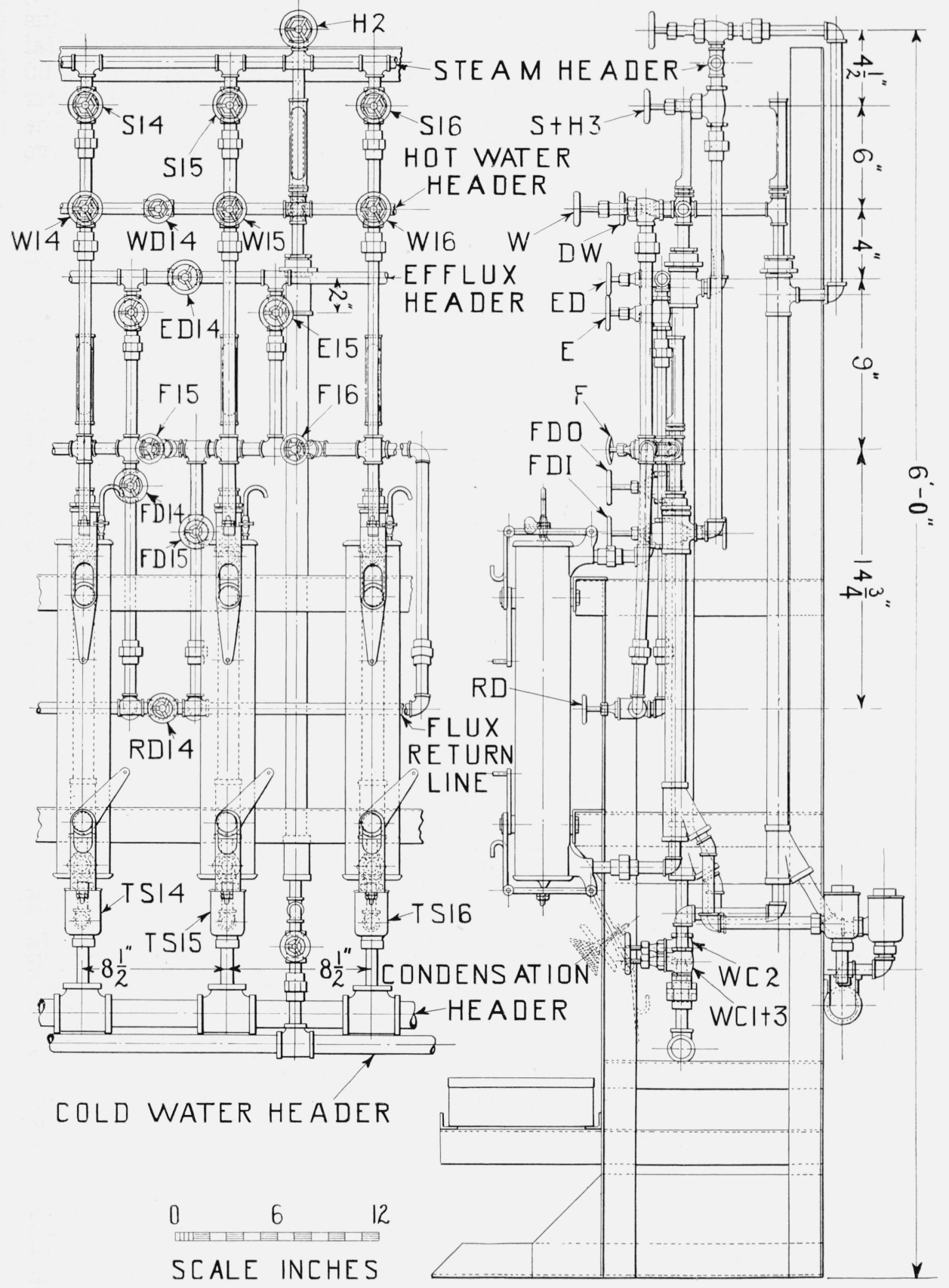

Figure 9.-Straight battery assembly.

(See appendix for explanatory text.) 
Journal of Research of the National Bureau of Standards

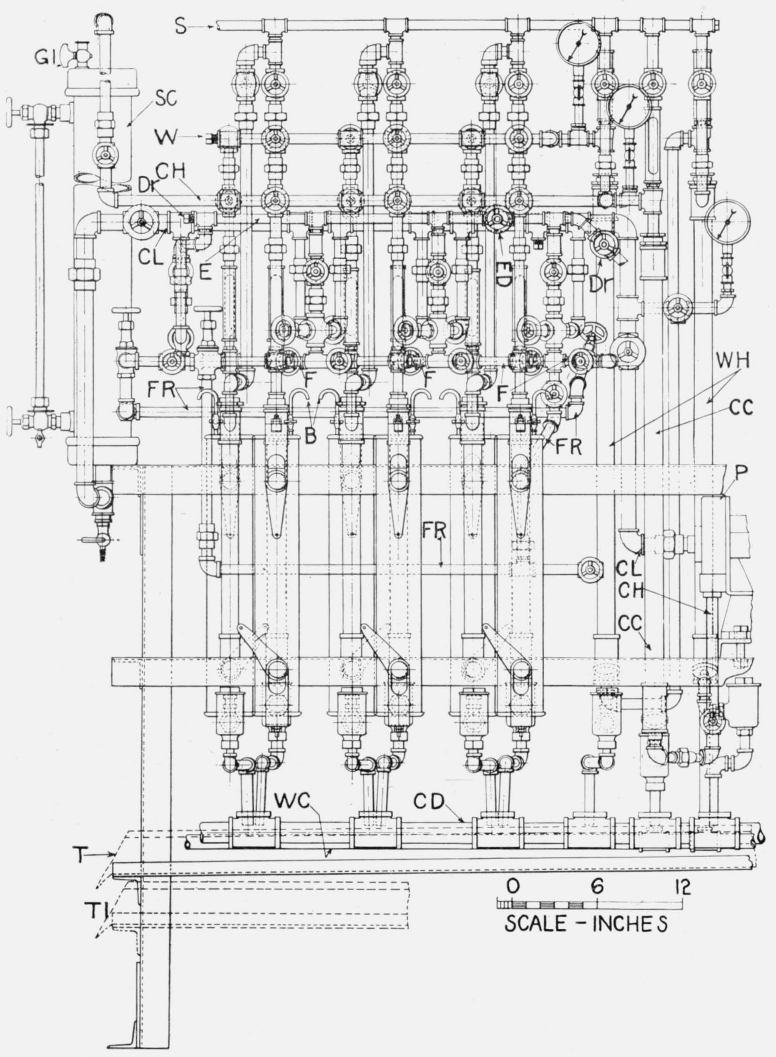

Research Paper 840

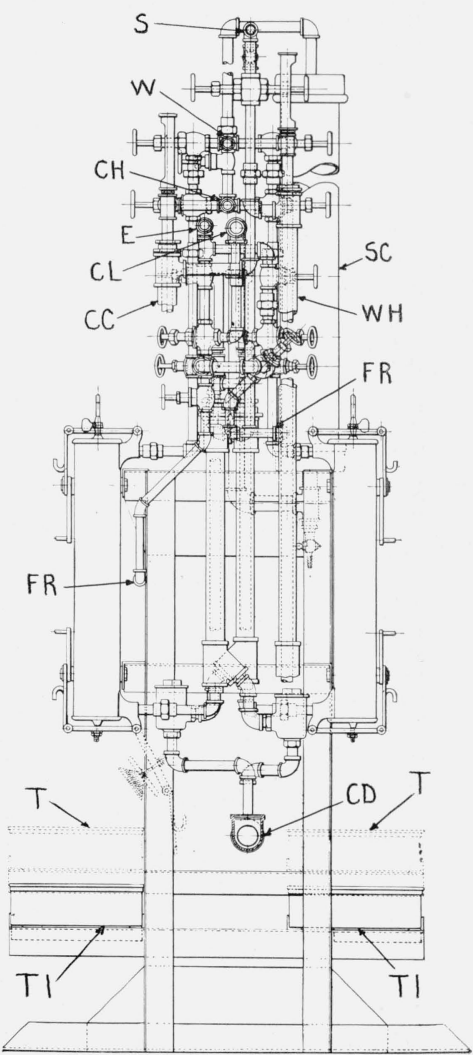

Figure 10.-Folded-battery assembly. (See appendix for explanatory text.) 


\section{Figure 4.-Flow diagrams with the circulatory system.}

At a the lower section of the column is being "preheated" by circulation of hot extract through the cells in parallel; at $\mathrm{b}$, the same by circulation of the hot extract through the cells in series. Reagent dosage may be applied in the same way, with or without heating.

At $\mathrm{c}$ the circulatory system is being used to apply reagent dosage to the material at the midale of the column. Notice that in a and b, a section of the battery becomes a part of the circulatory system; while in $c$ the circulatory system becomes, in effect, a unit of the battery placed directly in the course of the flux.

Figure 5.-Diagram of pipe connections, per cell, (a) for the straight battery arrangement, and (b) for the folded battery arrangement with circulatory system.

To bring out the fundamental simplicity of the connections in both cases, all the connections are placed in one plane and those pertaining to the middle cell are drawn in full lines. The relations of the contiguous cells in each case, and of the circulatory system also, in the folded arrangement, are indicated by broken lines.

The notation is as follows: $\mathrm{E}=$ efflux manifold; $\mathrm{F}_{1}, \mathrm{~F}_{2}, \mathrm{~F}_{3}=$ valve connections between flux and inlet manifolds; $F M=$ flux manifold; $I M=$ inlet manifold; $\mathrm{C}_{\mathrm{H}}=$ high-pressure circulation manifold; $\mathrm{C}_{\mathrm{L}}=\mathrm{low}_{\mathrm{O}}$ pressure circulation manifold; $S_{2}, S_{3}=$ steam inlets to calorisators; $X=$ valves which were not included in the experimental battery, but should be included if cell cut-out bridges are installed between flux manifolds, or if three tandem columns are to be operated on this installation with a separate efflux manifold for each column.

Figure 6.- Cell body, cast brass.

Construction and dimensions, with assembly view at left. Details of the attachments and fittings are indicated in figure 7, including special castings for constructing similar cells of standard brass tubing, which should yield cells of more uniform capacity.

Where uniform capacity is desired, however, it is suggested that the cast-brass cells be specified with machine finish inside, and with requisite tolerances as to variations in inside diameter and length. $\mathrm{A}=$ 3/16-inch drill; $\mathrm{B}=19 / 32$-inch drill, 3/8-inch-18NPT; $\mathrm{C}=5 / 16$-inch drill, 3/8-inch-16NC-2.

\section{FIGURE 7.-Cell attachments and fittings.}

Items 2 and 3. Special castings for bosses, when cells are constructed of brass tubing. Make 40 of thickness $L$ and 40 of thickness M. Material: Brass. Finish: As indicated. Dimensions: $\mathrm{H}=5 / 16$-inch drill, $3 / 8$-inch $-16 \mathrm{NC}-2 ; \mathrm{I}=1$ inch; $\mathrm{L}=1 / 4$ inch; $\mathrm{M}=5 / 16$ inch; $\mathrm{T}=$ radius of $\mathrm{O}$. $\mathrm{D}$. of tubing.

Item 4. Pipe boss and cover bracket. Make 40. Material: Cast brass. Finish: As indicated. Dimen sions: $\mathrm{D}=3 / 8$ inch; $\mathrm{E}=3 / 1 \mathrm{~s}$-inch drill; $\mathrm{F}=11 / 2$ inches; $\mathrm{H}=19 / 2$-inch drill, $3 / 6$-inch-18NPT; $\mathrm{K}=13 / 8$ to 11 inches; $N=5 / 8$ inch; radii as follows: $T=O$. D. of tubing; $X=1 \frac{1}{4}$ inches; $Y=21 / 4$ inches; $Z=11 \frac{1}{4}$ inches; $L=11 \frac{1}{2}$ inches.

Item 6. Yoke for doors and covers. Make 40. Material: Cast steel. Finish: Rough, except as indicated. Dimensions: $\mathrm{A}=413 / 16$ inches; $\mathrm{B}=7 / 16$ inch; $\mathrm{C}=1 / 2$ inch, $\mathrm{D}=3 / 8$ inch; $\mathrm{E}=3 / 8$ inch; $\mathrm{F}=1$ inch; $\mathrm{H}=3 / 16$ inch; $\mathrm{K}=5 / 16$ inch; $\mathrm{N}=5 / 6$ inch; over-all length not to exceed $51 / 2$ inches,

Item 8. Special toggle nut for securing door or cover to yoke. Make 40. Material: Steel. Finish: All over. Dimensions: $\mathrm{E}=$ no. 9 drill, $1 / 4-\mathrm{inch}-20 \mathrm{NC}-2 ; \mathrm{H}=1 / 2$ inch; radius of face curvature, $3 / 8$ inch.

Item 10. Doors and covers. Make 20 doors, 20 covers. Material: Cast brass. Finish: Rough, except as indicated. Dimensions: $\mathrm{I}=25,8$ inches; $\mathrm{L}=31 / 4$ inches; $\mathrm{X}=31 / 2$ inches; $\mathrm{V}=\mathrm{no}$. 9 drill, $1 / 4$-inch-20NC-2; $\mathrm{U}=80$ to $82^{\circ} ; \mathrm{K}=36$ inch; $\mathrm{N}=1,8$ inch; $\mathrm{T}=38 \mathrm{inch} \mathrm{Z}=3$-inch radius. For covers only: $\mathrm{A}=1 / 2 \mathrm{inch} ; \mathrm{E}=7$ inch; $\mathrm{H}=21 / 64$-inch drill, $1 / 8$-inch-27NPT; $\mathrm{M}=$ circle of 20 -mesh brass wire cloth, $3 / 4$-inch diameter, cupped as indicated and soldered to cover as protection to pipe-tapped opening; 1/4- by 2 -inch flat-head machine screw in center opening, with head sweated into countersink to form water-tight joint. For (bottom) doors only: $\mathrm{A}=3 / 4$ inch; strainer (item 15) sweated into countersink and $1 / 4$ - by 2 -inch steel machine screw sweated into strainer at one operation, to form water-tight joint.

Item 11. Jack-lock hasp. Make 40. Material: Cold-rolled steel or hard brass. Finish: Inside curve surface marked $\mathrm{f}$ to be polished; straight surfaces marked $\mathrm{f}$ to be machine finished. Dimensions: J, radius= 0.500 to 0.501 inch; $K$, radius $=0.75$ inch; $E=3 / 16$ inch; $F$, radius=approximately $3 / 8$-inch, for finger hold; $\mathrm{H}=3 / 4$ inch; $\mathrm{L}=327 / 32$ inches; $\mathrm{N}=5 / 8$ inch; $\mathrm{W}=11 / 2$ inches; $\mathrm{P}=1 / 8$ inch.

Item 12. Special shoulder bolt for jack-lock axle. Make 40. Material: Tool steel. Finish: All over, surface marked $\mathrm{f}$ to be polished. Dimensions: $\mathrm{D}=3 / 6$-inch- $16 \mathrm{NC}-3$ min. number full threads, $4 ; \mathrm{I}=5 / 16$ inch; K, diam of axle bearing, 0.495 to 0.490 inch; $M$, note that length of axle bearing is $1 / 64$ inch greater than thickness $T$ of crank (item 13); $N$, thickness of washer-face of head $=1 / 32$ inch; $V$, thickness of hexagon head $=1 / 4$ inch

Item 13. Jack-lock crank. Make 40. Material: Tool steel, one piece, excent handle. Finish: All over, reamed hole and polished drum. Dimensions: $\mathrm{E}$, hole $1 / 8$-inch eccentric; $\mathrm{H}$, hole reamed to smooth surface, diam. 1/2 inch $\pm 0.002 ; \mathrm{F}$, thickness and width of drum flange, one side only, as indicated, 1/16 inch; J=diam. of drum, cylindrical surface polished, 1 inch; $P$, width of surface, $9 / 64$ inch; $L=33 / 4$ inches; $T=25 / 64$ inch; $\mathrm{W}=11,2$ inches.

Item 15. Strainer. Make 20. Material: Cast brass or bronze. Dimensions: $\mathrm{E}=1 / 4$-inch drill; $\mathrm{F}=15 / 16$ inches; $\mathrm{L}=25 \% 8$ inches; $\mathrm{T}=3 / 32$ inch; $\mathrm{U}=80$ to $82^{\circ} ; \mathrm{H}=1 / 8$ inch drill, $25 /$ in. ${ }^{2}$ to $1 / 4$ inch from apex (at bottom as drawn).

Item 17. Gasket. Make 200. Material: Red rubber. Dimensions: $\mathrm{H}=25 \%$ inches; $\mathrm{E}=31 \frac{1}{4}$ inches; $\mathrm{T}=$ $3 / 32$ inch.

Item 18. Gooseneck. Make 20. Material: Seamless drawn-copper tubing. Dimensions: $\mathrm{E}=5 / 16$-inch O.D., $1 / 32$-inch wall; $\mathrm{H}=1$ inch; $\mathrm{F}=1 / 2$ inch; $\mathrm{K}=1^{\circ}$; to be silver-soldered to nipple of $1 / 8$-inch pet cock after turning latter to I.D. of tubing.

\section{Figure 8.- Heater, funnels, and troughs.}

Item 1. Heater assembly, as first constructed. Make 20 of 24 -inch length and 3 of 36 -inch length. Material: Inside duct of brass, 3/8-inch iron pipe size; bottom fitting, standard 3/8-inch brass elbow; $D=1 / 2$ - by $11 / 2$-inch brass nipple, threaded one end only, and reamed to O.D. of $3 / 8$-inch brass pipe, to which it is sweated with silver solder in the position indicated; $\mathrm{H}=3 / 4$ - by $3 / 8$ - by 36 -inch brass tee; $2=$ expansion joint consisting of packed stuffing-box assembly, the component parts of which are presented in item $2 ; \mathrm{F}=1$ by 1 - by $3 / 8$-inch galv. tee; $\mathrm{E}=1$ - by $1 / 2$ - by $3 / 8$-inch galv. wye fitting, or 1 -inch wye bushed to equivalent size. Dimensions: $\mathrm{A}=41 / 2$ inches; $\mathrm{B}=17$ inches in the 24 -inch calorisators applied to the cells, and 29 inches in the 36 -inch water and juice heaters.

Item 2. Stuffing-box details. Twenty-three sets required, except as replaced by item 3 below. Material: Brass, either cast or turned from hexagon and round brass stock. Finish: As indicated. Dimensions: $\mathrm{A}=1 \frac{112}{2}$ inches; $\mathrm{B}=3 / 4$ inch; $\mathrm{C}=11 / 4$ inch; $\mathrm{G}$, undercut, not wider than $1 / 8$ inch; $\mathrm{D}=3 / 6$ inch; $\mathrm{E}=2$ inches; $\mathrm{F}=$ $13 / 8$ inch es; $\mathrm{H}=0.68$ inch (or slightly greater than O.D. of $3 / 8$-inch brass pipe); $\mathrm{J}$, undercut, not wider than 18 inch; $\mathrm{K}=1 / 4$ inch; $\mathrm{L}=1 \frac{1}{8} 8$-inch p. d. $-12-\mathrm{NS}-2 ; \mathrm{P}=1$-inch $-11 \frac{112 \mathrm{NPT}}{\mathrm{N}}$ 


\section{2}

Item 3. Cyclone. Alternate form of expansion joint used in later installations, one unit replacing $\mathrm{D}$ and $\mathrm{E}$, and another unit replacing 2 and $\mathrm{F}$, of the heater assembly. Forty-six required. Material: Cast iron. Finish: Rough, except as indicated. Dimensions: A, eccentricity of steam connection $=0.75$ inch \pm 0.05 ; $\mathrm{B}$, length of $1 / 2$-inch-14NPT $=1 / 6$ inch; $\mathrm{C}=133$ inches; $\mathrm{D}=1 \frac{1}{18} 8$ inches; $\mathrm{E}$, depth of stufflng box $=3 / 4$ inch; $\mathrm{F}$, length of 1 -inch-111/2NPT $=9 / 16$ inch; $\mathrm{G}=23 / 32$-inch drill, $1 / 2$-inch-14NPT; $\mathrm{H}=0.68$ inch (or O. D. of $3 / 8$ inch brass pipe); I, length of cored race=1 inch; $J=158$ inches; $K$, length exclusive of gland and stud bolts, not to exceed $27 / 8$ inches; $\mathrm{L}=115 / 16$ inches; $\mathrm{M}=1$-inch-111/2NPT; $\mathrm{N}=$ no. 9 drill, $1 / 4$-inch $-20 \mathrm{NC}-2 ; 0=5 / 16^{-}$ inch drill; $\mathrm{T}$, minimum thickness of stuffing-box bottom $=3 / 16$ inch.

Item 4. Charging funnel. Three required. Materials: Skew cone, hard sheet brass of 0.35 to $0.52 \mathrm{~mm}$ thickness; plates and gate, ditto, approximately $1 / 8$ inch in thickness; spreader bars between plates, about 0.025 inch thicker than gate; neck of seamless drawn-brass tubing, $25 \%$ inches O.D., 0.065 to 0.049 -inch wallthickness. Dimensions: $\mathrm{A}=2 \frac{1}{2}$ inches; $\mathrm{D}=101 / 2$ inches; $\mathrm{H}=8 \frac{1}{2}$ inches; $\mathrm{E}=25 / 6$ inches; $\mathrm{G}=$ about 0.025 inch less than $\mathrm{S} ; \mathrm{T}=3 / 8$ to $7 / 16$ inch; $\mathrm{N}=1 / 2$ to $5 / 8 \mathrm{inch}$; turned-down portion of gate handle to form support even with neck of funnel, as indicated.

Item 5. Drip trough or troughs. One required for single-row straight-battery arrangement, two for folded-row arrangement. Material: Galvanized sheet iron for ordinary extractions, cold-rolled sheet brass for acid extractions; approximate thickness, 0.0375 inch. Dimensions: $\mathrm{F}$, width of fold at top, $1 / 2$ inch; $\mathrm{E}=2 \frac{1}{2}$ inches; $\mathrm{H}=1$ inch; $\mathrm{I}=30^{\circ} ; \mathrm{K}=45^{\circ} ; \mathrm{L}$, for straight battery $=15$ feet $41 / 2$ inches; for folded battery, $\mathrm{L}=9$ feet $3 \frac{1}{2}$ inches.

\section{Figure 9.-Straight-battery assembly.}

End elevation and section of front elevation, indicating devices for dividing the battery between cells 14 and 15. Similar means was provided between cells 10 and 11 . While the battery is divided at cells 14 and 15, valves WD14, ED14, RD14, and F15 are permanently closed, and valves FD14 and FD15 are operated in place of the valve F15.

Notation: Numerals following letters denote the cell (or heater) to which fitting is attached, or with which it is operated; $\mathrm{S}$ denotes steam valves; W, water (solvent) valves; $\mathrm{E}$, efflux manifold valves; F, flux line stop valves; $R$, flux return line valves; $D$, a valve which is provided solely for dividing the battery: those marked $\mathrm{O}$ are for controlling the flow of flood liquid out of a cell by way of a flux return line; those marked I are for controlling the flow from the flux return line into the cell; valves admitting steam to a water heater are marked $\mathrm{H} 2$ and $\mathrm{H} 3$; valves marked WC control the flow of cold water into the water heaters 1, 2, and 3, respectively; and finally, Ts denotes the steam traps.

\section{Frgure 10.-Folded-battery assembly.}

End elevation and section of side elevation drawn as though representing a 6-cell battery instead of a 20-cell battery. One only (ED) of the valves required for dividing the battery into separate folded units is indicated. Notice that slight inconsistencies appear between the two elevations, which in the main have been introduced for clarity of illustration. For example, the back flux return line is indicated at different levels in the two elevations; the circulation, efflux, and water manifolds are shown in section and the valve ED, the cold-water main, and the circulation pump are omitted, in the end elevation; and parts of the water and circulation heaters are cut away in the end view.

Notation: $\mathrm{B}=$ air bleeders; $\mathrm{CC}=$ circulation manifold; $\mathrm{CL}=\mathrm{low}$-pressure manifold; $\mathrm{Dr}=$ draw-off connection; $\mathrm{E}=$ efflux manifold; $\mathrm{ED}=$ efflux manifold divider valve; $\mathrm{F}=$ flux line; $\mathrm{FR}=$ flux return line; $\mathrm{GI}=$ gas inlet to scrubber; $\mathrm{P}=$ circulation pump, with pedestal and driver and most of base broken away; $\mathrm{S}=$ steam manifold; $\mathrm{SC}=$ scrubber or saturator, with gage glass and draincock; $\mathrm{T}=$ position of drip trough as planned; $\mathrm{TI}=$ position of drip trough as installed, the lower position being more convenient for discharging the cells, especially into the sample receivers; $\mathrm{W}=$ hot water (solvent) manifold; $\mathrm{WC}=$ cold-water main; $\mathrm{WH}=$ two- $^{-}$ pass water heater connecting cold-water main and hot-water manifold.

Washington, August 28, 1935. 